\title{
Modeling of Biodiesel Production from Rape-Seed Oil and Methanol
}

\author{
Shijun Chen ${ }^{1,2, a}$, Kang Zhao ${ }^{1, b, *}$ and Ying Tang, ${ }^{3, \mathrm{c}, *}$ \\ ${ }^{1}$ Department of Materials Science and Engineering, Xi'an University of Technology, Xi'an 710048, P \\ R China \\ ${ }^{2}$ College of Chemistry and Chemical Engineering, Xi'an Shiyou University, Xi'an 710065, China \\ asjchen@xsyu.edu.cn, b158737534@qq.com, 'tangying78@xsyu.edu.cn
}

Keywords: continuous process, modeling, biodiesel production, flowsheet

Abstract. A continuous process flowsheet for biodiesel production from rape seed oil under alkaline condition on a commercial scale was developed. Detailed operating conditions and equipment designs for the process were obtained. A technology assessment of the process was carried out to evaluate the technical benefits. Analysis showed that the alkali-catalyzed process using rape seed oil as the raw material required the fewest and smallest process equipment.

\section{Introduction}

The American Society for Testing and Materials (ASTM) defines biodiesel fuel as monoalkyl esters of long chain fatty acids derived from a renewable lipid feedstock, such as vegetable oil or animal fat. "Bio" represents its renewable and biological source in contrast to traditional petroleum-based diesel fuel; "diesel" refers to its use in diesel engines[1,2]. Biodiesel, as an alternative fuel, has many merits. It is derived from a renewable, domestic resource, thereby relieving reliance on petroleum fuel imports. Compared to petroleum-based diesel, biodiesel has a more advantaged combustion emission profile, such as low emissions of carbon monoxide, particulate matter and unburned hydrocarbons[3,4]. As an alternative fuel, biodiesel can be used in neat form or mixed with petroleum-based diesel. Biodiesel has a relatively high flash point (423K), which makes it less volatile and safer to transport or handle than petroleum diesel. It provides lubricating properties that can reduce engine wear and extend engine life[4,5]. In brief, these merits of biodiesel make it a good alternative to petroleum based fuel and have led to its use in many countries, especially in environmentally sensitive areas.

The most common way to produce biodiesel is by transesterification, which refers to a catalyzed chemical reaction involving vegetable oil and an alcohol to yield fatty acid alkyl esters (biodiesel) and glycerol (Fig.1). Triacylglycerols (triglycerides), as the main component of vegetable oil, consist of three long chain fatty acids esterified to a glycerol backbone. When triacylglycerols react with an alcohol (e.g., methanol), the three fatty acid chains are released from the glycerol skeleton and combine with the alcohol to yield fatty acid alkyl esters (fatty acid methyl esters or FAME). Glycerol is produced as a by-product. Methanol is the most commonly used alcohol because of its low cost and is the alcohol of choice in the process developed in our study. In general, a large excess of methanol is used to shift the equilibrium far to the right. Transesterification reactions can be alkali-catalyzed, acid-catalyzed or enzyme-catalyzed. The first two types have received the greatest attention and are the focus of this article [6-9]. To date it has only been carried out on the laboratory scale and therefore will not be further discussed herein. The most common way to produce biodiesel is alkali-catalyzed.

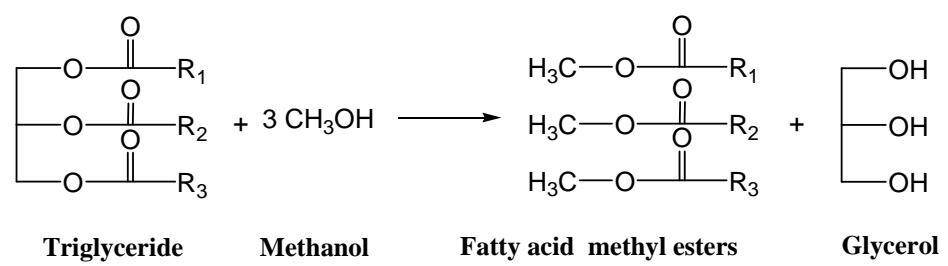

Fig. 1 Schematic representation of the transesterification of triglycerides (Rape-seed oil) with methanol to produce fatty acid methyl esters 


\section{Results and discussion}

\section{Fundamental}

A study of alkali-catalyzed transesterification on the laboratory scale has been carried out in our laboratory. A reaction temperature $333 \mathrm{~K}$ and a 6:1 molar ratio of methanol to Rape-seed oil were done. The kinetics of the alkali-catalyzed system was also studied .Based on their results, approximately 90\%-98\% oil conversion to methyl esters was observed within $90 \mathrm{~min}$. In order to speed up the reaction, Boocock suggested the addition of tetrahydrofuran (THF) as a co-solvent to minimize mass transfer resistance [5]. After the reaction, different separation techniques to purify the biodiesel product from the other products were investigated. In terms of the purity and yield of the biodiesel product, they concluded that the use of hot water washing at 323K was the best way to obtain a high purity (99\%) and yield (86\%) of the biodiesel product.

\section{Process design}

At continuous process were designed and simulated. Process flowsheet along with the properties of main streams are presented in Fig. 2. The materials of construction required for the main processing units in each of the process are summarized in Table 1. It is well known that alkali-catalyzed transesterification was less corrosive to process equipment than the acid-catalyzed process, when the concentration of sodium hydroxide is less than $50 \mathrm{wt} \%$, from ambient temperature to 368K carbon steel can be used. Peterson studied a batch process to produce biodiesel from rape seed oil using 0.2 $w t \%$ potassium hydroxide, in which stainless steel was used for the transesterification reactor. Taking a conservative approach, stainless steel was used for the transesterification reactor in the designs for the alkali-catalyzed processes in this study. So the material of construction of other equipment in the alkali-catalyzed processes was carbon steel.

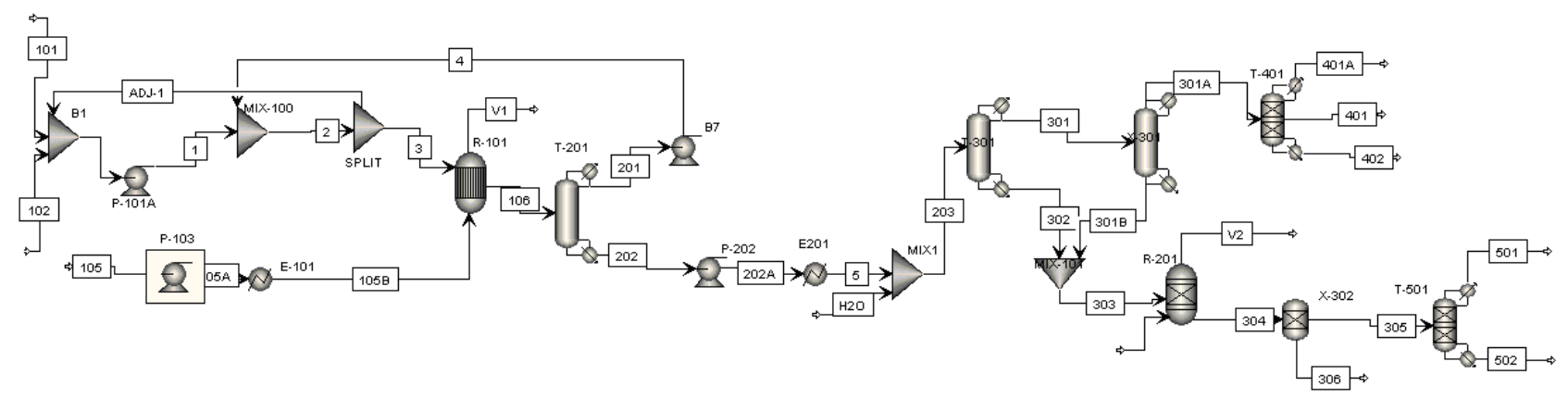

Fig. 2. Alkali-catalyzed process to produce biodiesel from rap seed oil

Table 1 Heng materials count and component mass fraction

\begin{tabular}{|c|c|c|c|c|c|c|c|c|c|c|c|c|c|c|c|}
\hline Stream name & 101 & 102 & 103 & $105 B$ & 106 & 201 & 202 & $301 \mathrm{~A}$ & 305 & 306 & $401 \mathrm{~A}$ & 401 & 402 & 501 & 502 \\
\hline temperature & 25 & 26.6 & 25 & 60 & 60 & 29 & 122 & 60 & 60 & 60 & 194.1 & 194.1 & 415 & 56 & 113 \\
\hline Pressure(kpa) & 100 & 400 & 100 & 400 & 400 & 20 & 30 & 110 & 110 & 110 & 10 & 10 & 20 & 40 & 50 \\
\hline Molar flow(kg/h) & 3.71 & 7.13 & 0.25 & 1.2 & 8.5 & 3.4 & 5.1 & 3.6 & 2.0 & 0.01 & 0.1 & 3.4 & 0.06 & 0.42 & 1.5 \\
\hline $\begin{array}{l}\text { Liquid volumeflow } \\
\qquad\left(\mathrm{m}^{3} / \mathrm{h}\right)\end{array}$ & 0.15 & 0.29 & 0.006 & 1.17 & 1.44 & 0.14 & 1.3 & 1.2 & 0.102 & 0.005 & 0.009 & 1.14 & 0.06 & 0.01 & 0.09 \\
\hline $\mathrm{CH}_{3} \mathrm{OH}$ & 1 & 0.970 & 0 & 0 & 0.09 & 1 & 0.006 & 0.003 & 0.035 & 0 & 0 & 0.388 & 0 & 0.36 & 0 \\
\hline Oil & 0 & 0 & 0 & 0 & 0.042 & 0 & 0.04 & 0.045 & 0 & 0 & 0 & 0 & 1 & 0 & 0 \\
\hline FAME & 0 & 0 & 0 & 1 & 0.779 & 0 & 0.855 & 0.853 & 0 & 0 & 0.505 & 0.998 & 0 & 0 & 0 \\
\hline Glycerol & 0 & 0 & 0 & 0 & 0.082 & 0 & 0.09 & 0.88 & 0.085 & 0 & 0 & 0 & 0 & 0 & 0.83 \\
\hline $\mathrm{NaOH}$ & 0 & 0.003 & 1 & 0 & 0.008 & 0 & 0.008 & 0.008 & 0.016 & 0 & 0 & 0 & 0 & 0 & 0 \\
\hline $\mathrm{H}_{2} \mathrm{O}$ & 0 & 0 & 0 & 0 & 0 & 0 & 0 & 0 & 0 & 0 & 0.106 & 0.002 & 0 & 0.64 & 0.17 \\
\hline $\mathrm{H}_{3} \mathrm{PO}_{4}$ & 0 & 0 & 0 & 0 & 0 & 0 & 0 & 0 & 0 & 0.005 & 0 & 0 & 0 & 0 & 0 \\
\hline $\mathrm{Na}_{3} \mathrm{PO}_{4}$ & 0 & 0 & 0 & 0 & 0 & 0 & 0 & 0 & 0 & 0.095 & 0 & 0 & 0 & 0 & 0 \\
\hline
\end{tabular}


To assess the commercial feasibilities of the proposed process, complete process simulations were first carried out. The process simulation software, Aspen Plus was used in this research. The procedure for process simulation mainly involve defining chemical components, selecting a thermodynamic model, determining plant capacity, choosing proper operating units and setting up input conditions(flow rate, temperature, pressure, and other conditions). Information on most components, such as methanol, glycerol, sulfuric acid, sodium hydroxide and water, is available in the Aspen Plus component library. Regarding the rap seed oil feedstock, canola oil was considered as the raw material because it is the major rep seed oil. Because oleic acid is the major fatty acid in canola oil, triolein $\left(\mathrm{C}_{57} \mathrm{H}_{104} \mathrm{O}_{6}\right)$ was chosen to represent canola oil in the Aspen Plus simulation. Accordingly, methyl oleate $\left(\mathrm{C}_{19} \mathrm{H}_{36} \mathrm{O}_{2}\right)$ was taken as the resulting biodiesel product and its properties were available in the Aspen Plus component library. The use of a thermodynamic/activity model is NRTL.

\section{Alkali-catalyzed process using rap seed oil}

\section{Transesterification}

A continuous alkali-catalyzed process flowsheet using rap seed oil was developed (Fig. 2). The reaction was carried out with a 6:1 molar ratio of methanol to oil, $1 \%$ sodium hydroxide (based on oil), $333 \mathrm{~K}$ and $400 \mathrm{kPa}$. Fresh methanol (stream 101 at $117 \mathrm{~kg} / \mathrm{h}$ ), recycled methanol (stream 1201 at 111 $\mathrm{kg} / \mathrm{h}$ ) and anhydrous sodium hydroxide (stream 103 at $10 \mathrm{~kg} / \mathrm{h}$ ) were mixed prior to being pumped into reactor R-101 by pump P-101. Rap seed oil (stream 105) was heated in exchanger E-101 before entering R-101. In R-101, 95\% of oil was assumed to be converted to FAME, producing glycerol as a by-product. Stream 106 from the reactor was introduced to methanol distillation T-201.

\section{Methanol recovery}

In T-201, five theoretical stages and a reflux ratio of 2 were used to obtain a good separation between methanol and other components. Stream 201 was a pure methanol distillate, containing $94 \%$ of the total methanol in stream 106. Vacuum distillation was used to keep the bottom temperature under 423K. Pure methanol (stream 1201) was mixed with fresh make-up methanol (stream 101B) and then charged back into reactor R-101. Bottom stream 202 was sent to washing column T-301 after being cooled in exchanger E-201 to 333K.

\section{Water washing}

The purpose of this step was to separate the FAME from the glycerol, methanol and catalyst. Although separation using a gravity settler was proposed by Krawczyk, a complete separation could not be achieved based on our simulation results. Consequently, a water washing column (T-301) with four theoretical stages was used in this study. The FAME in stream 203 was separated from the glycerol, methanol and catalyst by adding $11 \mathrm{~kg} / \mathrm{h}$ water (298K). The amounts of unconverted oil, methanol and water in stream 301A were all less than 6\%. All of the glycerol remained in the bottom stream $303(128 \mathrm{~kg} / \mathrm{h})$, which contained 81\% glycerol, 8\% water, 3\% methanol and 9\% sodium hydroxide. The main components of stream 301A (1184 kg/h) were FAME (85\%) and water (10\%). Therefore, the load of T-401 was increased because of the presence of more water in the feed stream 301A. Bottom stream 303 (173kg/h) contained 60\% glycerol, 32\% water and 6\% sodium hydroxide. However, regardless of which model was used, the simulation results indicated that adding the proper amount of water could lead to almost complete separation between the FAME and glycerol phase.

\section{FAME purification}

In order to obtain a final biodiesel product adhering to ASTM specifications (greater than 99.6\% pure), FAME distillation T-401 with four theoretical stages and a reflux ratio of 2 were used. Stream 301A from T-301 was forwarded to T-401. T-401 was operated under vacuum to keep temperatures low enough to prevent degradation of the FAME. A partial condenser was used to provide easy separation of the FAME from water and methanol in the column overhead. Water and methanol were removed as vent gases (stream 401A). FAME product (99.65\% purity) was obtained in stream 401 as a liquid distillate $\left(194^{\circ} \mathrm{C}\right.$ and $\left.10 \mathrm{kPa}\right)$. Unconverted oil remained at the bottom of T-401. Since only a small amount of unconverted oil (52 kg/h) was left, it was treated as a waste. When oil conversion in 
reactor R-101 was low and oil recycling was necessary for waste reduction, a cooler and a pump were required to pump the unconverted oil back to the transesterification reactor. Superheated high pressure steam was the heating medium for the reboiler.

\section{Alkali removal}

Stream $303(128 \mathrm{~kg} / \mathrm{h})$ was fed to neutralization reactor R-201 to remove sodium hydroxide by adding phosphoric acid (100\% purity). The resulting Na3PO4 was removed in gravity separator $\mathrm{X}-302$. When potassium hydroxide is used as an alkali catalyst, the resulting potassium phosphate may be used as a valuable byproduct.

\section{Glycerin purification}

After removing the sodium hydroxide, stream 305 contained $85 \%$ glycerol. If a glycerin by-product with a higher grade (e.g., 92\%) was preferred, this stream would pass to T-501 for further removal of water and methanol by distillation.

\section{Waste treatment}

The compositions of streams 401A, 402 and 501 are listed in Fig. 2. Because of their small flows, these streams were treated as hazardous gas or liquid wastes. However, reusing these streams may be advantageous in the future, especially for larger scale processes. For example, stream 501 can be returned to T-301 as a washing solvent instead of fresh water. Recovery of the solid waste stream 306 from X-302 as a possible fertilizer credit is also feasible. Overall, these changes offer potential approaches for reducing waste treatment loads.

\section{Conclusion}

For a biodiesel production, a flowsheet for continuous alkali-catalyzed process using rap seed oil as the raw material was designed and simulated. From the technical assessment, all of the process proved to be feasible for producing a high quality biodiesel product and a top-grade glycerin by-product under reasonable operating conditions. The alkali-catalyzed process using rap seed oil was the simplest with the least amount of process equipment but had a higher raw material cost than other processes. Methanol distillation was carried out immediately following transesterification to reduce the load in downstream units in process. In general, the feasibility of a plant includes technological aspect. Consideration must be taken of the sensitivity of the results to the thermodynamic model used and the significance of model influence on the results.

\section{Acknowledgements}

This work was financially supported by grants from National Natural Science Foundation of China (21306149) and Scientific Research Plan Projects of Shaanxi Education Department (2013JK0646).

\section{References}

[1] A.K. Agarwal, L.M. Das: J. Eng. Gas Turbines Power Vol. 123 (2001), p. 440

[2] D.G.B. Boocock, S.K. Konar, V. Mao, C. Lee, S. Buligan: J. Am. Oil Soc. Chem Vol. 75 (1998), p. 1167

[3] L. Jeromin, E. Peukert, G. Wollmann: US Patent 4698186 (1987)

[4] M. Fangrui, A.H. Milford: Bioresource Technol Vol. 70 (1999), p. 1

[5] L.C. Meher, D. Vidya Sagar, S.N. Naik: Renew. Sust. Energ. Rev Vol. 10 (2006), p. 248

[6] Y. Tang, M. Meng, J. Zhang, Y. Lu: Applied Energy Vol 88 (2011), p. 2735

[7] Y. Tang, J. Zhang, J. Xua, Y. Lu: J. Bio. Mater. \& Bioen Vol 5 (2011), p. 552

[8] Y. Tang, X. Gu, G. Chen: Envir. Chem. Lett Vol 11 (2013), p. 203

[9] Y. Tang, J. Xu, J. Zhang, Y. Lu, J Cleaner Produ Vol 42 (2013), 198 